\title{
Evaluating the impact of climate on snow- and ice-melt dynamics in the Taillon basin, French Pyrénées
}

\author{
David M. Hannah, Glenn R. McGregor \\ School of Geography, University of Birmingham, Birmingham B152T T, England
}

\begin{abstract}
This pilot study adopts a computer-assisted synoptic typing methodology to evaluate the totality of climatic influences on snow- and ice-melt dynamics within a small cirque basin in the French Pyrénées. The synoptic categories identified possess contrasting large-scale atmospheric circulation patterns and surface energy budgets which generate differential ablation responses. Continental air masses yield consistently high melt. Advection of moist maritime air also produces elevated but more variable ablation due to air-mass transitions. The two observed local valley circulation types show melt to be higher under nocturnal katabatic drainage than for anabatic wind flows associated with development of daytime ridge-top cumulus.
\end{abstract}

\section{INTRODUCTION}

While numerous researchers have focused on the detail of the glacier surface energy balance (Hay and Fitzharris, 1988a; Braithwaite and Olesen, 1990; Munro, 1990; Ishikawa and others, 1992; McGregor and Gellatly, 1996) and some have attempted to relate variation in the surface energy budget to the variability of melt across snow and ice surfaces (Munro and Young, 1982; Escher-Vetter, 1985; Arnold and others, 1996), few have attempted to investigate the impact of synoptic-scale weather patterns on snow and ice hydrology. Such analyses are considered important, because air masses have associated with them typical weather patterns and hence accumulation and ablation regimes which influence glacier mass balance. Since the linkages between glacier hydrology and climatic processes are currently poorly understood, we suggest that a synoptic climatological approach, which characterises similarities in general circulation patterns and active meteorological elements within a holistic framework, will facilitate an assessment of climate's influence on snow- and ice-melt dynamics. This approach will allow the impact of the totality of weather on snow and ice ablation to be determined. The underlying assumption of the synoptic climatological approach is that distinct synoptic-scale patterns and their associated air masses possess differential abilities to drive snow and ice ablation. Therefore, certain synoptic-scale weather categories will be associated with high ablation rates, whereas others will be associated with reduced melt. In addition, as weather events frequently have associated with them clear diurnal patterns, the temporal distribution of surface melt over the daily cycle is likely to be determined by the prevailing synoptic-scale conditions. This will have an influence on the timing and volume of meltwater input to the glacier drainage system and ultimately proglacial stream discharge. While linking synoptic conditions to proglacial stream-flow has potential applications for meltwater runoff modelling, the main purpose of this paper is to present the results of a pilot application of a synoptic climatological approach, which identifies air masses (synoptic categories) and their snow- and ice-melt relationships, to understanding the impact of large-scale climate on glacier ablation dynamics in the Pyrénées.

\section{STUDY AREA}

The data on which this pilot study is based were collected between 25 June and 26 August 1995 at Glacier du Taillon, Cirque du Gavarnie, French Pyrénées. Glacier du Taillon is situated $143.5 \mathrm{~km}$ from the Atlantic Occan in a northeast-facing cirque (aspect of $35^{\circ}$ ) at $43^{\circ} 06^{\prime} \mathrm{N}, 00^{\circ} 01^{\prime} \mathrm{E}$. This remnant glacier covers an area of $20 \mathrm{ha}$ and spans an altitudinal range of approximately $500 \mathrm{~m}$, with the snout at $2526 \mathrm{~m}$ a.s.l. and the cirque headwall at $3022 \mathrm{~m}$ a.s.l. (Gellatly and others, 1995). Glacier du Taillon was selected because it satisfies most of the criteria outlined by Ostrem and Brugman (1991) for glacier mass-balance investigations. The glacier also lies in a region which is at the southern margin of contemporary European valley glaciation where glacial systems possess a great deal of climatic sensitivity (McGregor and Gellatly, 1996). Recent historical fluctuations of Glacier du Taillon have been discussed by Gellatly and others (1995).

\section{METHODS}

\section{Data collection}

For this study, $6 \mathrm{~h}$ average data from the central station of a diamond-shaped network of five automatic weather stations (AWSs), set up as part of a wider project to investigate the spatio-temporal characteristics of the surface energy balance and melt response, were used. This station was chosen because spatial correlation analyses have shown this site is most representative of the general spatial variability in glacier ablation. Details on the meteorological variables monitored, the instrumentation used and the nature and frequency of data logging are given in Table 1. A feature of 
Table 1. Field monitoring and instrumentation

\begin{tabular}{|c|c|c|c|}
\hline \multicolumn{4}{|c|}{ Meteorological elements } \\
\hline Variable & Instrumentation & Sensor height (m) & Units \\
\hline $\begin{array}{c}\text { Atmospheric } \\
\text { pressure }\end{array}$ & $\begin{array}{l}\text { Silicon capacitive } \\
\text { pressure sensor }\end{array}$ & 1.0 & mbar \\
\hline Net radiation & Net radiometer & 1.0 & $\mathrm{~W} \mathrm{~m}^{-2}$ \\
\hline $\begin{array}{l}\text { Minimum relative } \\
\text { humidity }\end{array}$ & Hygrometer & 0.5 & $\%$ \\
\hline $\begin{array}{l}\text { Maximum relative } \\
\text { humidity }\end{array}$ & Hygrometer & 0.5 & $\%$ \\
\hline $\begin{array}{l}\text { Mean air } \\
\text { temperature }\end{array}$ & Thermistor & 0.5 & $\mathrm{C}$ \\
\hline Mean wind speed & Three-cup anemometer & 0.5 & $\mathrm{~ms}^{-1}$ \\
\hline Glacier melt & \multirow[t]{2}{*}{ Unit } & \multicolumn{2}{|c|}{ Conversion } \\
\hline \multicolumn{3}{|l|}{ Instrumentation } & \\
\hline Ablatometer & $\mathrm{mV}$ & \multicolumn{2}{|c|}{ ms.w.e. $15 \mathrm{~min}^{-1}$} \\
\hline \multicolumn{4}{|c|}{ Data logging and storage } \\
\hline \multicolumn{2}{|c|}{ Instrumentation } & \multicolumn{2}{|l|}{ Logging interval } \\
\hline \multicolumn{2}{|c|}{ Campbell 21X Data Logger } & \multicolumn{2}{|l|}{10 s scan } \\
\hline \multicolumn{2}{|c|}{ Campbell sm716 Storage Module } & \multicolumn{2}{|l|}{$15 \mathrm{~min}$ averages } \\
\hline
\end{tabular}

this study was the use of two ablatometers (Lewkowicz, 1985; Munro, 1990) for monitoring snow and ice melt. These were situated $10 \mathrm{~m}$ down-glacier from the AWS and $15 \mathrm{~m}$ apart, between 2 July and 24 August. The ablatometer offers some advantages over the traditional ablation measurement techniques, reviewed by Müller and Keeler (1969), as it has a high degree of precision (within $0.5 \mathrm{~mm} \mathrm{~h}^{-1}$, equivalent to a net energy exchange of $\left.<20 \mathrm{~J} \mathrm{~cm}^{-2} \mathrm{~h}^{-1}\right)$ and unlike other methods produces a continuous record. The ablatometer was designed to minimise its influence on melt.

\section{Analytical techniques}

Air-mass types (synoptic categories) were identified using a combination of VARIMAX (orthogonal) P-mode principal components analysis (PCA) (Richman, 1986) followed by cluster analysis (CA) (Brazel and others, 1992). The statistical background to PCA has been discussed by Jolliffe (1990), while its utility in synoptic climatology has been outlined by Yarnal (1992). The input data consisted of $57 \mathrm{~d}$ of $6 \mathrm{~h}$ means for each of the six meteorological variables $(n)$ for each day $(N)$, yielding a matrix of 1368 cases $(24 \times 57)$.

\section{RESULTS}

\section{Principal components and cluster analyses}

Performance of P-mode rotated VARIMAX PCA and the application of standard principal components retention criteria and component loading interpretation techniques (Jolliffe, 1993) resulted in six principal components (PCs) being retained and physically interpreted. Their interpretations are as follows: $\mathrm{PC}_{1}$, morning sky and thermal conditions; $\mathrm{PC}_{2}$, pressure; $\mathrm{PC}_{3}$, overnight thermal-advection index; $\mathrm{PC}_{4}$, overnight sky conditions and net radiation loss; $\mathrm{PC}_{5}$, evening sky conditions and energy inputs; $\mathrm{PC}_{6}$, daylight wind speed. The component scores (weighted summed values whose magnitudes are dependent on the weather observations for each day and the PC loadings) for the six PCs were computed and clustered, resulting in the identification of ten synoptic categories. For clustering, the average linkage technique was used, as this method minimises the intra-cluster variance while maximising inter-cluster variance (Kalkstein and others, 1987).

\section{Emergent synoptic categories}

Once identified, the ten synoptic categories were evaluated based on their diurnal meteorological patterns (Fig. 1), daily meteorological summary statistics (Table 2) and analyzed surface pressure charts (Fig. 2). In order to establish whether the identified synoptic categories possessed differential energy available for melt and ablation characteristics, the surface energy balance (Hay and Fitzharris, 1988a; Ishikawa and others, 1992) and ablation rates (from the ablatometer data, expressed in $m$ snow w.e.) were calculated for the days comprising each of the synoptic categories. Since discussion of all ten synoptic categories is beyond the scope of this paper, the four most frequent categories will be discussed, that is $1,2,3$ and 6 .

Synoptic category 1. Building maritime anticyclone tropical maritime air mass

Very warm and dry conditions prevail overnight; however, air temperatures fall and moisture builds from $1200 \mathrm{~h}$. Clear skies occur after $0900 \mathrm{~h}$ but net radiation is variable in the afternoon, indicating broken cloud moving over the basin. Wind speeds are generally calm throughout the day and pressure decreases moderately after $1200 \mathrm{~h}$. Precipitation fell on eight of the 13 days in this synoptic category. These conditions are associated with a trough of low pressure moving away from the Pyrénées, while a well-developed high pushes in over the Bay of Biscay from the Atlantic Ocean. This advects moist maritime air over the Pyrénées.

\section{Synoptic category 2. Iberian heat low tropical continental air mass (local circulation type)}

Low energy inputs with some cloud are apparent in the morning, with building cloud soon after $1200 \mathrm{~h}$. Air temperatures are invariant and relatively cool. Very moist atmospheric conditions prevail due to low-level cloud. Calm conditions persist with atmospheric pressure rising moderately throughout the day. Rainfall occurred on 9 of the 21 days. These conditions are associated with local valley circulation produced when a heat low trough extends from North Africa over the Iberian Peninsula.

\section{Synoptic category 3. Double low continental air mass}

Early morning cloud occurs prior to $0900 \mathrm{~h}$, followed by relatively clear conditions with building energy inputs to around $1200 \mathrm{~h}$. Transient cloud occurs in the afternoon, often associated with rain (six of the nine days). Air temperature rises from moderately warm $\left(8^{\circ} \mathrm{C}\right)$ to warm $\left(14^{\circ} \mathrm{C}\right)$ and remains moderately warm $\left(8-10^{\circ} \mathrm{C}\right)$ throughout the night. Wind speeds are low with almost calm conditions. Relative humidity is steady around $65 \%$. These conditions are associated with a stable, moderately dry air mass, on the eastern side of an area of low pressure over the Bay of Biscay. There is also low pressure over France and the Iberian Peninsula, into which dry continental air is advected from the north.

Synoptic category 6. Northwest European and Iberian Peninsula high (mixed local and large-scale circulation type)

Low overnight humidities associated with dry northerly air and katabatic drainage are temporarily replaced by moist 
valley circulation during the day. A well-established high pressure over northern France and western Europe stretches into the Mediterranean. This returns dry continental air to the area at night, allowing radiative cooling and re-establishment of katabatic drainage. Over the Iberian Peninsula, a weak centre of high pressure exists, while over North Africa a heat low trough builds. Atmospheric pressure gradients are very slack, facilitating the development of strong nocturnal katabatic drainage. This category eventually develops into category 2.

\section{DISCUSSION}

The relationship between the synoptic categories and snow- and ice-melt dynamics is analyzed in relation to both the diurnal meteorological patterns and surface energy balance (Fig. 1). The contributions of the energy-balance components to melt are given in Table 3 . Fluxes are considered to be positive when directed towards the surface (Ishikawa and others, 1992).

Generally, net radiation appears to dominate the energy budget, but especially for synoptic categories 2 and 3 . The magnitude of net radiation for category 3 is much greater than that for category 2 (Table 3), as would be expected given their meteorological characteristics. Noticeable inputs from sensible heat under warm (category 1 ) and windy (category 6) conditions are evident, the latter being typically related to nocturnal katabatic drainage. Latent heat is gen-
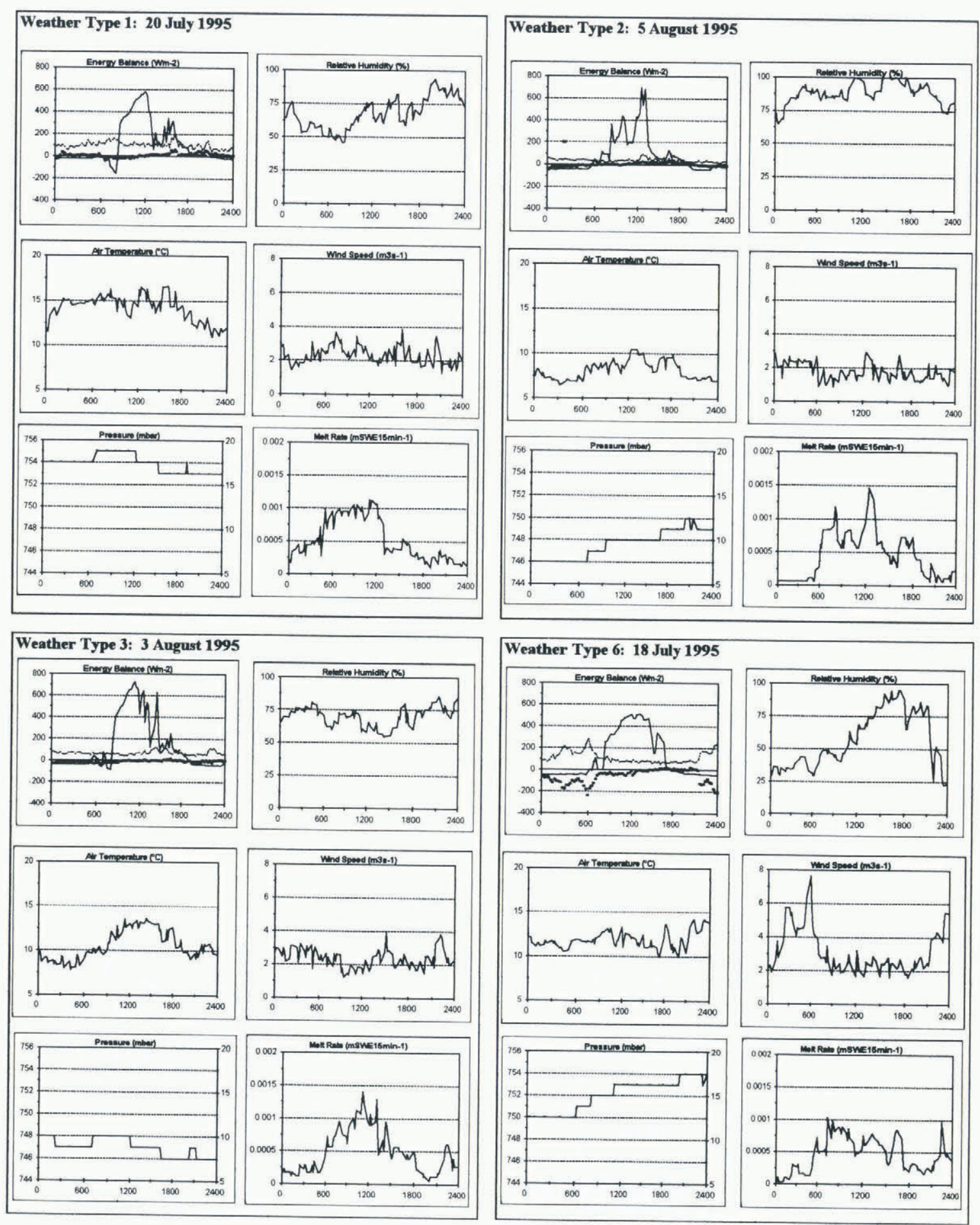

Fig. 1. Diurnal meteorological patterns and associated glacier melt responses (energy-balance components: solid line = net radiation; dashed line $=$ sensible heat; solid circles $=$ latent heat $).$ The $x$ axis is in hours Greenwich Mean Time. 
Table 2. Daily mean summary statistics for weather types ( $W S=$ wind speed; $R H=$ relative humidity; $Q^{*}=$ net radiation; standard deviation in parentheses)

\begin{tabular}{|c|c|c|c|c|c|c|}
\hline Weather & Air temp. & WS & $\operatorname{Max} R H$ & $\operatorname{Min} R H$ & $Q^{*}$ & Pressure \\
\hline & C & $\mathrm{ms}^{-1}$ & $\%$ & $\%$ & $\mathrm{MJ} \mathrm{m}^{-2}$ & mbar \\
\hline \multirow[t]{2}{*}{1} & 9.9 & 2.3 & 72.9 & 65.7 & 11.10 & 749.15 \\
\hline & $(2.9)$ & $(0.9)$ & $(19.2)$ & (20.3) & (5.04) & (3.1) \\
\hline \multirow[t]{2}{*}{2} & 6.9 & 2.1 & 81.2 & 73.8 & 7.36 & 746.8 \\
\hline & $(2.3)$ & (1.12) & $(15.9)$ & (17.3) & $(2.62)$ & (1.9) \\
\hline \multirow[t]{2}{*}{3} & 8.9 & 2.0 & 77.6 & 71.1 & 8.02 & 747.0 \\
\hline & $(2.2)$ & (0.8) & $(13.7)$ & (15.1) & (3.81) & (2.4) \\
\hline \multirow[t]{2}{*}{4} & 5.0 & 2.0 & 84.7 & 79.8 & 6.00 & 743.0 \\
\hline & $(2.1)$ & (1.0) & (12.6) & $(14.0)$ & (1.53) & $(2.9)$ \\
\hline \multirow[t]{2}{*}{5} & 6.6 & 1.5 & 73.2 & 66.3 & 6.55 & 751.6 \\
\hline & (3.7) & $(0.8)$ & $(20.9)$ & (21.9) & $(1.72)$ & (3.4) \\
\hline \multirow[t]{2}{*}{6} & 12.9 & 3.4 & 41.6 & 33.5 & 10.92 & 751.9 \\
\hline & $(1.7)$ & (1.4) & $(20.2)$ & (19.2) & $(3.80)$ & (1.8) \\
\hline \multirow[t]{2}{*}{7} & 8.5 & 1.5 & 67.8 & 55.6 & 13.95 & 751.5 \\
\hline & (2.1) & $(0.5)$ & $(25.8)$ & (31.1) & $(\mathrm{N} / \mathrm{A})$ & (0.9) \\
\hline \multirow[t]{2}{*}{8} & 9.8 & 1.9 & 40.5 & 27.9 & 10.49 & 745.7 \\
\hline & $(1.5)$ & $(0.6)$ & (23.3) & (19.9) & $(\mathrm{N} / \mathrm{A})$ & $(0.9)$ \\
\hline \multirow[t]{2}{*}{9} & 7.0 & 2.9 & 73.9 & 68.5 & 5.18 & 748.7 \\
\hline & (1.5) & (1.9) & $(19.2)$ & $(20.0)$ & $(\mathrm{N} / \mathrm{A})$ & (1.0) \\
\hline \multirow[t]{2}{*}{10} & 4.1 & 2.6 & 85.1 & 80.5 & 5.71 & 749.0 \\
\hline & (1.1) & (2.6) & $(19.2)$ & $(22.1)$ & $(2.32)$ & (1.6) \\
\hline
\end{tabular}

erally unimportant in terms of the energy available for melt, with the exception of category 6 when the warm windy night-time conditions produced large evaporative losses. In terms of energy availability, categories 1 and 3 appear to provide the requisite meteorological conditions for elevated melt rates. The mean ablation rates by category are shown in Figure 3, illustrating a range of ablation responses to the different meteorological conditions associated with the various synoptic categories. One-way analysis of variance revealed category 2 melt rates to be significantly lower (0.05 level) than those for categories 1 and 6 . This is due to the lower energy available for melt due to the cool, overcast, calm conditions that exist when valley circulation predominates under Iberian heat low conditions.

Although no significant difference between melt rates was found for categories 1,3 and 6 , the synoptic patterns (Fig. 2) producing high melt rates are quite different, as is the partitioning of the energy balance (Table 3). In terms of the intra-category melt-rate variability, category 3 possesses the lowest, perhaps suggesting that continental air masses consistently produce high melt rates. This contrasts with categories 1 and 6 , which display considerable variation due largely to air-mass transitions associated with changing synoptic-scale conditions. A further factor that may well explain intra-category variability in melt rates is glacier surface albedo, which decreases over the melt season as the

\section{Weather Type 1 \\ (14 August 1995)}

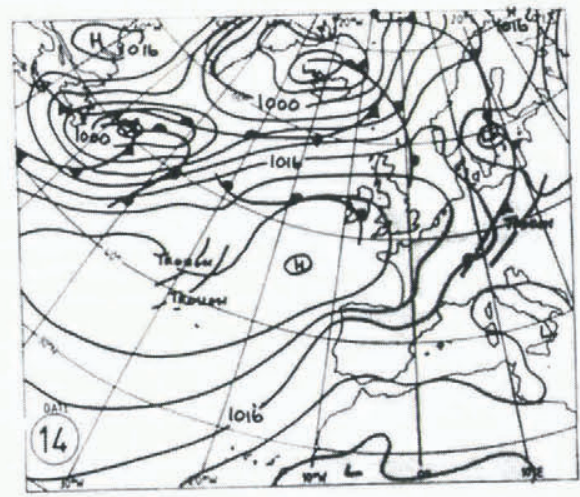

Weather Type 3

(3 August 1995)

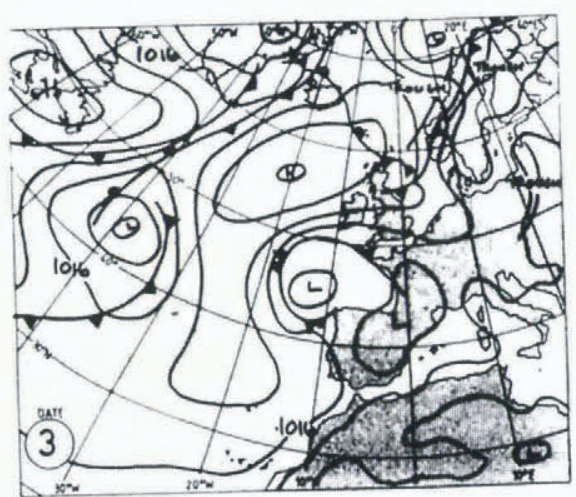

\section{Weather Type2 \\ (9 August 1995)}

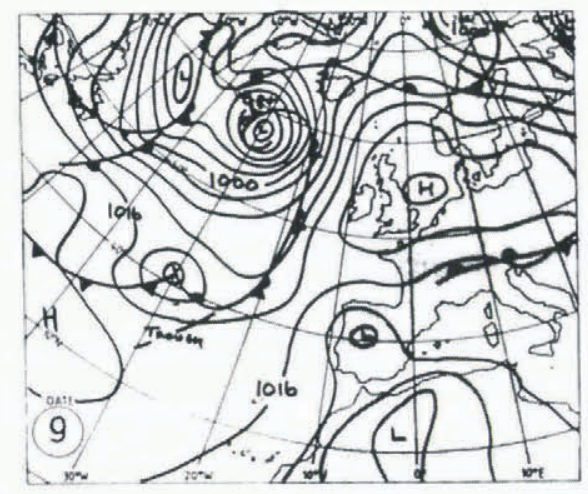

\section{Weather Type 6 \\ (24 July 1995)}

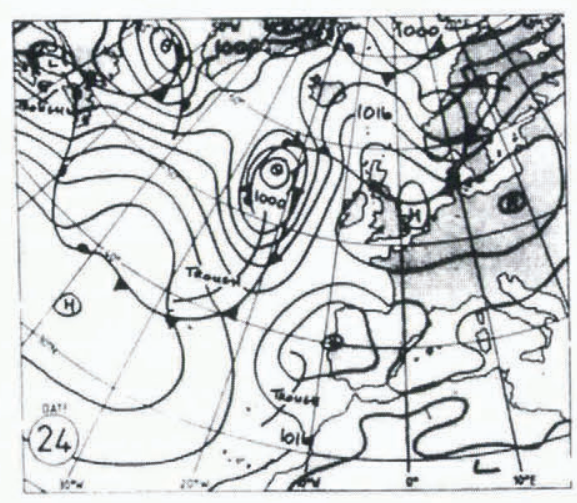

Fig. 2. Analyzed surface-pressure charts. 


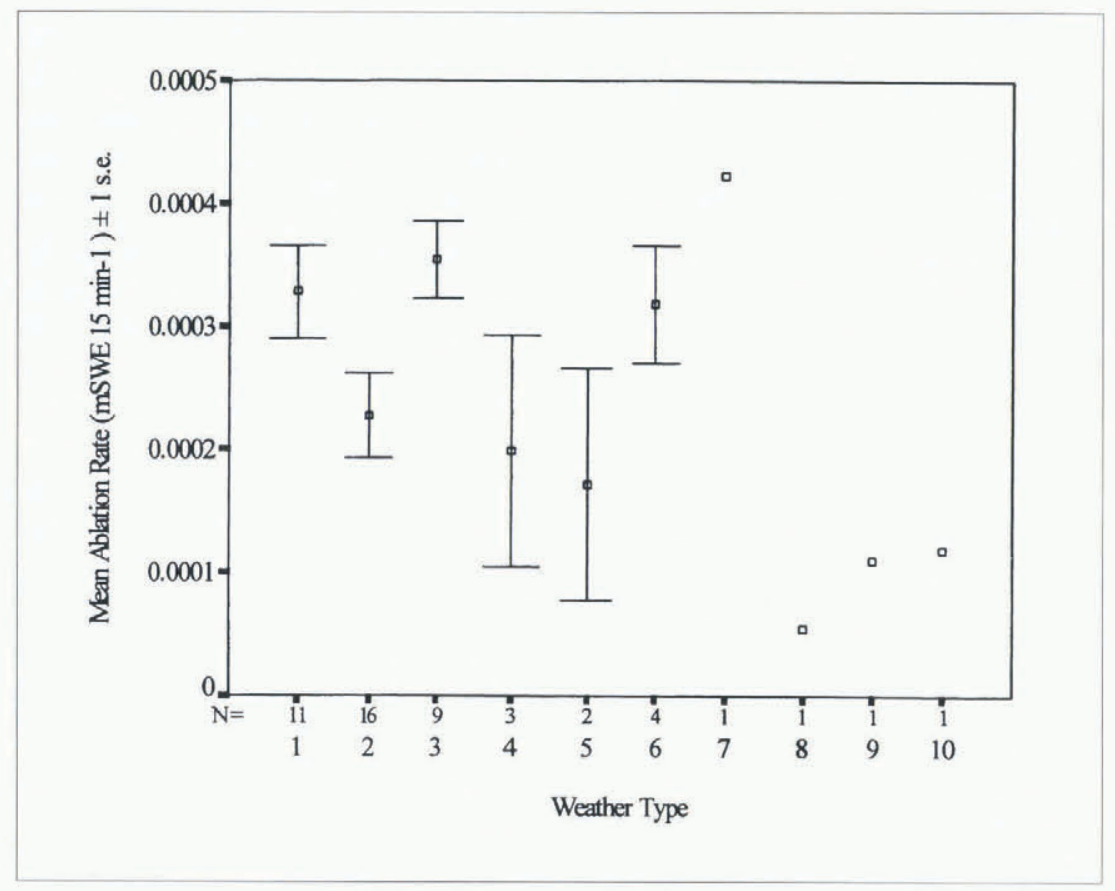

Fig. 3. Weather type mean ablation rates.

Table 3. Contribution of energy-balance components to snow and ice melt $\left(\mathrm{MJ} \mathrm{m}^{-2} \mathrm{~d}^{-}\right.$; percentage contribution in parentheses) $\left(Q^{*}=\right.$ net radiation; $Q_{\mathrm{h}}=$ sensible heal; $Q_{\mathrm{e}}=$ latenl heat; $Q_{\mathrm{m}}=$ total energy available for melt)

\begin{tabular}{cccccc}
\hline Weather lype & Day & $Q^{*}$ & $Q_{\mathrm{h}}$ & $Q_{e}$ & $Q_{\mathrm{m}}$ \\
\hline \multirow{2}{*}{1} & 201 & 9.501 & 8.792 & 0.755 & 19.048 \\
& & $(49.8)$ & $(46.2)$ & $(4.0)$ & \\
2 & 217 & 7.760 & 3.637 & 0.003 & 11.400 \\
& & $(68.1)$ & $(31.9)$ & $(0.02)$ & \\
3 & 215 & 11.932 & 6.316 & -0.857 & 17.391 \\
& & $(65.0)$ & $(35.0)$ & & \\
6 & 199 & 10.812 & 9.804 & -5.061 & 15.555 \\
& & $(52.5)$ & $(47.5)$ & & \\
& & & & & \\
\end{tabular}

clean snow melts to expose debris-laden ice. Synoptic categories for which net radiation dominates the energy available for melt and remains high throughout the day, such as category 3 , should be more effective in producing high melt rates later in the season due to increased energy absorption (e.g. on 2 July surface albedo was 0.54 with a corresponding ablation rate of $0.00015 \mathrm{~ms}$.w.c. $15 \mathrm{~min}$; while on 4 August albedo was 0.25 , resulting in a mean melt rate of $0.00041 \mathrm{~m}$ s.w.e. $15 \mathrm{~min}^{-1}$ ). Although the sample size is small, the melt rates associated with categories 8, 9 and 10 are comparatively low. These are most likely a product of large-scale weather patterns quite different from categories 1,3 and 6 .

\section{CONCLUSIONS}

Despite the limitations relating to the interpretation of the current analysis, especially the limited sample size for development of the synoptic categorisation and the lack of consideration of the accumulation season, we have identified groups of synoptic categories that possess differential abilities in terms of snow and ice ablation. At the qualitative level, three broad groups appear to exist which describe a trend from high (categories 1,3,6 and 7) to medium (categ- ories 2, 4 and 5) to low (categories 8, 9 and 10) melt rates. Of interest are the contrasting melt rates for the two local valley circulation types, which produce higher melt rates under strong nocturnal katabatic drainage (category 6) compared to the lower melt rates associated with well-developed anabatic flows and the development of daytime ridge-top cumulus (category 2). These contrasts are related to subtle synoptic-scale contrasts in pressure distribution, especially in the region of the Iberian Peninsula.

Since this pilot study's results and the work of others (Yarnal, 1984a, b; Hay and Fitzharris, 1988b; Bazel and others, 1992; Aizen and Aizen, 1993) demonstrate that large-scale synoptic patterns influence local glacier climate, establishing the nature of the links between the two scales should be a priority, if glacier response to predicted climate change is to be assessed. Such a synoptic climatological approach is considered valid, because shifts in the regional synoptic climatology will produce changes in surface hydroclimatological processes. These will manifest themselves in the form of changes in the seasonal melt rates and thus the spatial distribution of snow and ice resources, which may be significant in climatically sensitive regions such as the Pyrénées. Further work is planned to investigate this research issue. We invite comments on the proposed approach.

\section{ACKNOWLEDGEMENTS}

The authors wish to thank A. G. Lewkowicz for the loan of an ablatometer, and also everyone who helped with data collection during the field season. D. M. Hannah gratefully acknowledges the School of Geography, University of Birmingham, for providing funding.

\section{REFERENCES}

Aizen, V. B. and E. M. Aizen. 1993. Glacier runoff estimation and simulation of streamflow in the peripheral territory of central Asia. Intemalional Association of Hydrological Sciences Publication 218 Symposium at Kathmandu 1992 - Snow and Glacier Hydrology), 167-179.

Arnold, N. S., I. C. Willis, M. J. Sharp, K. S. Richards and W. J. Lawson. 1996. A distributed surface energy-balance model for a small valley glacier. I. Development and testing for Haut Glacier d'Arolla, Valais, Swit- 
zerland. J. Glaciol., 42 (140), 77-89.

Braithwaite, R.J. and O. B. Olesen. 1990. A simple energy-balance model to calculate ice ablation at the margin of the Greenland ice sheet. 7. Glaciol., 36 (123), 222-228.

Brazel, A. J., F. B. Chambers and L. S. Kalkstein. 1992. Summer energy balance on West Gulkana Glacier, Alaska, and linkages to a temporal synoptic index. Z. Geomorphol., Supplementband 86, 15-34.

Escher-Vetter, H. 1985. Energy balance calculations for the ablation period 1982 at Vernagtferner, Oetztal Alps. Ann. Glaciol., 6, 158-160.

Gellatly, A. F., J. M. Grove, A. Bücher, R. Latham and W. B. Whalley. 1994. Recent historical fluctuations of the Glacier du Taillon, Pyrénées. Phys. Geogr., $15(5), 399-413$.

Hay, J. E. and B. B. Fitzharris. 1988a. A comparison of the energy-balance and bulk-aerodynamic approaches for estimating glacier melt. f. Glaciol., $34(117), 145-153$.

Hay, J. E. and B. B. Fitzharris. 1988b. The synoptic climatology of ablation on a New Zealand glacier. 7. Climatol., 8, 201-215.

Ishikawa, N., I. F. Owens and A. P. Sturman. 1992. Heat balance characteristics during fine periods on the lower parts of the Franz Josef Glacier, South Westland, New Zealand. Int. f. Climatol., 12, 397-410.

Jolliffe, I. T. 1990. Principal components analysis: a beginners guide - I: introduction and application. Weather, 45, 375-382.

Jolliffe, I. T. 1993. Principal components analysis: a beginners guide - II: pitfalls, myths and extensions. Weather, 48, 246- 253.

Kalkstein, L. S., G. Tan and J. A. Skindlov. 1987. An evaluation of three clustering procedures for use in synoptic climatological classifications. $\mathcal{f}$.
Climate Appl. Meteorol., 26, 717-730.

Lewkowicz, A. G. 1985. Use of an ablatometer to measure short-term ablation of exposed ground ice. Can. 7. Earth Sci., 22 (12), 1767-1773.

McGregor, G. R. and A. F. Gellatly. 1996. The energy balance of a melting snow pack in the French Pyrénées during warm anticyclonic conditions. Int. f. Climatol., 16, 1-8.

Müller, F. and C. M. Keeler. 1969. Errors in short-term ablation measurements on melting ice surfaces. f. Glaciol., 8 52), 91-105.

Munro, D. S. 1990. Comparison of melt energy computations and ablatometer measurements on melting ice and snow. Arcl. Alp. Res., 22 (2), 153-162.

Munro, D. S. and G.J. Young. 1982. An operational net shortwave radiation model for glacier basins. Water Resour. Res., 18 2), $220-230$.

Ostrem, G. and M. Brugman. 1991. Glacier mass-balance measurements. A manual for field and office work. Saskatoon, Sask., Environment Canada. National Hydrology Research Institute. (NHRI Science Report 4.)

Richman, M. B. 1986. Rotation of principal components. J. Climatol., 6 (3), $293-335$.

Yarnal, B. 1984a. Relationships between synoptic-scale atmospheric circulation and glacier mass balance in south-western Canada during the International Hydrological Decade, 1965-74. J. Glaciol., 30 (105), 188-198.

Yarnal, B. 1984b. Synoptic-scale atmospheric circulation over British Columbia in relation to the mass balance of Sentinel Glacier. Ann. Assoc. Am. Geogr., 74(3), 375-392.

Yarnal, B. 1992. Synoptic climatology in environmental analysis: a primer. London, Bellhaven Press.

MS received 13 May 1996 and accepted in revised form 30 June 1997 